\title{
Gait Disturbance, CTCAE
}

National Cancer Institute

\section{Source}

National Cancer Institute. Gait Disturbance, CT CAE. NCI Thesaurus. Code C143496.

A disorder characterized by walking difficulties. 